\title{
Um Mestre de Rigor: Manoel Luiz Salgado Guimarães e a delimitação do campo de estudos de historiografia no Brasil
}

\author{
One Master of Rigor: Manoel Luiz Salgado Guimarães and the \\ delimitation of the field of studies in historiography in the Brazil
}

\author{
Durval Muniz de Albuquerque Júnior \\ durvalaljr@gmail.com \\ Professor titular \\ Universidade Federal do Rio Grande do Norte \\ Rua Professora Gipse Montenegro, 2017/1305 - Capim Macio \\ 59080-060 - Natal - RN \\ Brasil
}

\begin{abstract}
Resumo
Texto de homenagem, ele trata de situar a importância da obra e do trabalho acadêmico de Manoel Luiz Salgado Guimarães, historiador brasileiro falecido em 2010, para a consolidação do campo dos estudos de historiografia na Universidade brasileira. Definindo-o como um mestre, e um mestre de rigor, o texto procura avaliar os aspectos inovadores do trabalho desenvolvido pelo professor Manoel Luiz Salgado Guimarães, bem como indicar os caminhos que foram abertos pela sua militância nos campos do ensino e da pesquisa. Aborda as inúmeras facetas de seu trabalho e se esforça para traçar um perfil, não só do acadêmico, mas do homem público, do cidadão, e porque não do amigo que foi fundamental com seus escritos, com suas aulas, com suas atividades de orientação, para a obra e a vida dos muitos que lhe conheceram. Este é um texto que busca fazer o luto, da melhor maneira que é possível, fazendo da morte de alguém o estímulo para a vida, para a continuidade de uma herança, instaurando a responsabilidade naqueles que ficaram de seguir a obra inacabada, refundindo vida naquele que nos deixou vivo uma importante parte de si mesmo: o pensamento.
\end{abstract}

\section{Palavras-chave}

Campo historiográfico; Conhecimento histórico; Cultura historiográfica.

\begin{abstract}
Text of homage, it tries to situate the importance of the opus and the academic work of Manoel Guimarães Luiz Salgado, Brazilian historian who died in 2010, to the consolidation of the field of studies in the historiography of the Brazilian University. Defining him as a master, and a master of rigor, the text seeks to evaluate the innovative aspects of the work developed by Professor Manoel Luiz Salgado Guimarães as well as indicating the paths that were opened by his activism in the fields of teaching and research. It addresses the many facets of his work and strives to draw a profile, not only the academic, but the public man, the citizen, and why not, of the friend who was fundamental in his writings, with their classes, with their orientation activities, for the work and lives of many who knew him. This is a text that seeks to mourn, as best it is possible, making the death of someone stimulus for life, for the continuity of an inheritance, providing responsibility on those who are supposed to continue the unfinished work, recasting life in that who left us alive an important part of himself: his thought.
\end{abstract}

\section{Keywords}

Historiography Field; Historical knowledge; Historiographical culture.

Recebido em: 18/7/2013

Aprovado em: 24/9/2013 
Paul Ricoeur dedicou uma seção de seu livro $A$ Memória, A História e $O$ Esquecimento àqueles que ele nomeou de mestres de rigor: Michel Foucault, Michel de Certeau e Norbert Elias (RICOEUR 2007, p. 210-219). Eles são assim denominados, segundo Ricoeur, por terem, cada um a seu modo, radicalizado a exigência de rigor por parte do discurso dos historiadores profissionais, tornando-os rebeldes à modelização em voga na escola dos Annales. Esta cobrança de um maior rigor por parte daqueles que produzem história teria se dado mediante a problematização, em grande medida ainda inédita, da própria escrita da história, daquilo que Michel de Certeau chamou de "operação historiográfica" (CERTEAU 2002, p. 65-122). Estes autores teriam deslocado o olhar da crítica das fases documental e da explicação/compreensão para a fase da representação historiadora, onde a própria capacidade de explicação e de compreensão dos eventos, por parte dos historiadores, se materializava. Abandonam-se as discussões intermináveis em torno de qual seria o documento mais raro, mais legítimo, mais verdadeiro, mais fidedigno; abandonam-se as diatribes em torno do melhor método, da mais adequada metodologia, do aparato conceitual infalível que levaria a correta interpretação dos acontecimentos, para pensar a "operação historiográfica" como o momento em que a fabricação do arquivo, a escolha de recursos de interpretação se encontram e se materializam no que seria a terceira fase do processo: a escritura. Partindo do já escrito, analisando o discurso historiográfico como um acontecimento, Michel Foucault se propõe a fazer, como de resto com os demais discursos das ciências humanas, a sua arqueologia: numa regressão, parte do discurso para encontrar as regras, as práticas discursivas e não-discursivas que presidem seu aparecimento, o não dito que permite e possibilita o que foi dito (FOUCAULT 1986, p. 153-222). Norbert Elias convoca a se encontrar para além dos discursos historiográficos, para além dos eventos tais como narrados pelos historiadores, eventos vistos como singulares, irrepetíveis e excepcionais, a regularidade da formação social que Ihes serviu de solo e de húmus (ELIAS 1975). Michel de Certeau, ao mesmo tempo em que toma a prática historiadora como um trabalho, como uma operação produtora de sentido para o outro que é o passado e seus sujeitos, este outro que embora morto ainda nos interpela, propõe que percebamos que o discurso historiográfico é antecedido, permitido e fabricado a partir de um lugar social: o lugar de historiador, que não é um lugar neutro ou vazio, mas é um lugar que implica a observância de um conjunto de códigos e de regras, exige uma disciplina, que repercute sobre aquilo que esse profissional escreve sobre o passado. Escrita que também obedece a modelos culturalmente válidos, em uma dada época e que lança mão de recursos literários e ficcionais sem os quais a produção do relato sobre o passado, sua invenção seria impossível.

Estamos aqui hoje para lembrar aquele que pode ser chamado o nosso mestre de rigor. Aquele que, assim como Foucault, Certeau e Elias - companhias das quais partilhou ao longo de incontáveis dias de leituras, escrita e ensino -, contribuiu para que os historiadores, notadamente os historiadores brasileiros, perdessem a inocência diante daquilo que fazem, prestassem maior atenção ao trabalho com a linguagem que realizam. Manoel Luiz Salgado Guimarães tem 
a mesma importância para uma maior exigência de rigor por parte daqueles que produzem historiografia no Brasil que aqueles que foram seus mestres para a historiografia ocidental contemporânea. Se Paul Ricouer, outra presença constante na produção acadêmica do mestre brasileiro, tivesse conhecido, como nós conhecemos, o Manoel Salgado professor de cursos de graduação e de pós- graduação, o orientador de monografias, dissertações e teses, o autor de textos meticulosamente escritos, eruditos, embasados em intermináveis horas de leitura e anotações, escritos e reescritos com a insaciável busca da perfeição, não hesitaria em colocá-lo na companhia da tríade que nomeou de mestres de rigor.

Manoel Luiz Salgado Guimarães é reconhecidamente um dos responsáveis principais pela afirmação do campo dos estudos de historiografia no Brasil. Ele, com muito afinco e apesar de muitos o aconselharem a fazer "história mesmo", "história de verdade", se empenhou na consolidação de um campo de pesquisa em torno daquelas problematizações que foram colocadas para os historiadores pelas obras não só de Foucault, Certeau, Elias, mas do próprio Ricoeur, de François Hartog, de Hayden White, de Roland Barthes, de Reinhart Koselleck, entre outros, que inquiriam o fazer história lá onde ela se materializa: na produção do texto, na narrativa, na escrita.

Suas pesquisas acadêmicas se debruçaram sobre a historicidade das formas de se escrever a história no Brasil, o que implicou pensar também, assim como fizeram seus mestres, na racionalidade que presidia essa prática em um dado momento, na historicidade das próprias regras que presidiram 146 a disciplina em nosso país, em pensar a história das instituições em que essas obras de história foram produzidas, em tratar das diferentes condições históricas que possibilitaram e convocaram dadas maneiras de se escrever a história entre nós, em abordar os contextos de recepção dessas obras, que estratégias políticas e narrativas as presidiram. A obra do Manoel Salgado, desde o texto sobre a historiografia produzida pelos membros do Instituto Histórico e Geográfico Brasileiro, que o tornou conhecido no mundo acadêmico (GUIMARÃES 1988) - texto exaustivamente citado e até plagiado entre seus pares, que se relacionava com o tema de sua Tese de Doutorado, escrita em alemão, que permaneceu inédita durante tanto tempo e que finalmente ganhou o formato de livro (GUIMARÃES 2011) -, foi sempre uma interrogação sobre os autores que fizeram a historiografia brasileira, sobre os lugares sociais e institucionais dessa produção, mas, principalmente, sua interrogação foi sobre a que usos políticos serviu a escrita da história em nosso país (GUIMARÃES 1989). Ao contrário do que fazia crer dadas críticas que recebia, a obra do Manoel foi uma obra radicalmente política, ela foi uma interrogação constante sobre o gesto político que marca o escrever a história, a dimensão política, mas também a dimensão ética e estética que está implicada no fazer historiográfico, daí porque gostasse tanto dos mestres citados por Ricoeur e do próprio Ricoeur, cujas reflexões sobre a historiografia também articulam essas três dimensões, sem deixar de ser, também, a pergunta pelo tipo de racionalidade que preside o texto em análise. Quem o conheceu sabe que, embora fosse uma pessoa bastante afetiva, sensível e emotiva, aspectos que não separava em sua vida 
de uma racionalidade e uma lucidez marcantes, em seus escritos predomina o Manoel Salgado racional, o homem das luzes, que não cessou de se interrogar sobre as repercussões desse movimento de ideias sobre a escrita da história.

Tanto em suas pesquisas, como em suas aulas, Manoel Salgado foi responsável por questionar a forma simplista com que alunos e pesquisadores do campo da história viam a relação entre linguagem e eventos do passado. Talvez por sua formação alemã, o mestre de rigor que ele veio a se constituir não se conformava com a ingenuidade daqueles que ainda pensavam a linguagem como um espelho, como dotada de uma transparência que permitia, com ela, dizer-se com certa dose de certeza a realidade do passado. Embora formado historiador na pátria do historicismo, no país de Leopold Von Ranke, talvez por isso mesmo, por também ser a pátria da hermenêutica moderna, por também ser a pátria daqueles nomeados por François Dosse de mestres da suspeita: Nietzsche, Freud e Marx, por ser a pátria de Heidegger e de Koselleck, Manoel Salgado tenha retornado ao Brasil disposto a por em suspeita, a questionar a persistência do historicismo e do positivismo no interior de nossa historiografia, mesmo naquela cujas inspirações foram a escola dos Annales e o marxismo. Para isso, tal como faz Foucault, utiliza-se da própria história, não da história das ideias, mas da história das regras de produção dos discursos sobre a história do Brasil, pondo em questão, com seus estudos, tal como Elias, a própria formação social brasileira, ao interrogar-se sobre o laço inextricável entre a produção do passado, as diversas formas de produção da memória e as condições históricas particulares de nosso país, que as possibilitaram. Ao invés de uma história da história no Brasil, marcada pela pergunta acerca das influências externas, pelas ideias fora e no lugar, pela indagação sobre a ideologia que a informou, a obra do Manoel se debruça sobre os próprios textos dos historiadores e questiona como foram fabricados, que operações e situações os tornaram possíveis. Seu trabalho nos ensinou a deslocar nosso olhar do que estava fora do texto para prestarmos atenção no próprio texto. Ele sempre convocou a todos, portanto, a uma atitude básica: a da leitura, prática de que tanto gostava. Temístocles Cezar atribui a proporcionalmente pequena obra deixada pelo Manoel, se comparada a outros de autores de sua geração, a sua paixão pela leitura. ${ }^{1}$ Mas não era qualquer leitura que ele requeria, era uma leitura meticulosa, rigorosa, detida. Assim como seus mestres, Manoel se debruçava sobre os textos, dava uma enorme atenção a eles não apenas por causa daquilo de que falam, os textos não eram para ele apenas uma via de acesso ao que estava para além deles, mas se debruçava sobre os textos vendo-os como aquilo que são: acontecimentos. Os textos não apenas falam ou remetem a acontecimentos, mas eles próprios são eventos, são marcas e restos deixados por uma dada temporalidade. Os textos vindos do passado o fascinavam, não apenas por falarem do passado, mas por serem em si mesmos o que, quase sempre, restou do passado e chegou até nossos dias. Quem foi seu aluno, orientando ou acompanhou de perto seu trabalho sabe do rigor que exigia para si e para os outros quando da leitura de um texto.

\footnotetext{
${ }^{1}$ Esta afirmação foi feita em conversa com o autor do texto.
} 
Essa atitude, só ela, talvez já justifique chamá-lo de mestre. Quem teve o privilégio de conhecê-lo bem sabe o quanto ele fez por merecer este título, essa honraria que talvez tenha sido a única que sempre procurou. Homem modesto e recatado, embora vaidoso como todos de nossa condição profissional, o Manoel foi um mestre nos vários sentidos dessa palavra: ele dominou como ninguém as artes de seu ofício, em todos os seus aspectos, como alguém que se debruçou criticamente sobre as implicações políticas, éticas e estéticas do que fazia, conseguiu aprimorar-se e atingir um grau de excelência em tudo que fazia, como poucos conseguiram entre nós; ele fez da arte de ensinar o centro de sua vida e de sua profissão, se não deixou uma obra escrita volumosa em formato de artigos e livros, deixou uma obra monumental em formato de horas e horas de aulas rigorosamente preparadas e brilhantemente executadas, nas conversas e palestras sempre educativas e formadoras, nas meticulosas e eruditas arguições que realizou em inúmeras bancas de avaliação de trabalhos de pós-graduação, e nas horas e horas dedicadas a orientação. Se considerarmos como sendo parte de sua obra, contra o que com certeza protestaria, todos os trabalhos que orientou, poderemos dimensionar corretamente o efeito Manoel Salgado para a historiografia brasileira. Embora em sua modéstia não se considerasse superior a ninguém, ele esteve à frente e acima de muitos de seu tempo, não apenas pelo seu saber, mas por suas atitudes, amparadas numa retidão ética inatacável. O Manoel foi um mestre não apenas naquilo que escrevia ou dizia, mas em como vivia, em como praticava sua profissão, em como se comportava em tudo aquilo que fazia, ele foi um mestre do viver. Ele em si mesmo servia de ensinamento. Todos aprendemos com ele, não apenas lendo os seus textos, ouvindo suas conferências, assistindo suas aulas, mas convivendo com ele. Com ele aprendi, por exemplo, o que é ser amigo, o que é ser companheiro, o que significa a amizade, o que significa gostar do outro apesar e por causa das diferenças. Como todo mestre, o Manoel serviu de guia para muitos, talvez por isso ainda hoje estejamos meio perdidos desde que ele partiu. Mas mestres não morrem, porque seus exemplos quedam imorredouros na memória daqueles que tiveram a sorte de serem seus aprendizes.

Dedicado como foi à arte de ensinar, o Manoel foi sempre um interessado nas discussões em torno do ensino da história e do gesto pedagógico envolvido na própria escrita da história (GUIMARÃES 2003b). Sua liderança política e acadêmica entre os historiadores brasileiros deveu-se a sua disposição em discutir não apenas a escrita da história, mas o ensino da história. Ensino onde também fazia-se presente o mestre de rigor que ele se tornou. Quem foi seu aluno sabe que essa era uma exigência constante e permanente do mestre, assim como também viria a cobrar daqueles que se tornariam, mais tarde, seus colegas de profissão. O rigor naquilo que se ensinava, a atenção para o detalhe, o combate a negligência ou a leniência que alguns queriam que fosse uma atitude típica da terra brasilis. Acima de tudo, tal como aprendeu com seus mestres, o rigor conceitual, a precisão histórica e de sentido no uso de cada conceito, a correção na análise das condições históricas em que cada texto foi produzido, a interrogação sobre a pertinência de cada afirmação feita. Embora simpático 
e generoso com seus alunos, um mestre que sempre se colocou ao lado e não acima de seus pupilos, o Manoel sempre emulou aqueles que o procurava no sentido de buscarem fazer formulações precisas, informadas e pertinentes sobre o que se estava discutindo. Embora recepcionasse bem a criatividade e a irreverência, exigia que elas fossem embasadas em sólidas informações e em pesquisa documental exaustiva.

A paixão pelo arquivo era outro traço que definia esse nosso mestre de rigor (GUIMARÃES 2010). Acusado por muitos de fazer um trabalho fácil, de gabinete, sem contato com a poeira e as traças indispensáveis para o batismo e reconhecimento do profissional da história, o Manoel foi também, nesse aspecto, um pioneiro, um fundador de práticas, além de fundador de discursividades. Lembro com que satisfação me anunciou que após frequentar os arquivos portugueses voltara ao país munido de uma preciosa documentação, que iria sustentar suas análises sobre as formas e práticas historiográficas do século XIX no Brasil, permitindo o cotejo com as tradições narrativas, com os modelos historiográficos, com o pensamento sobre a história correntes na península ibérica naquele século. Se dava enorme valor à biblioteca, a sua biblioteca, de onde saía material e inspiração para seus escritos sobre a história da historiografia brasileira, o Manoel também soube fazer do arquivo não só um lugar de frequentação e pesquisa, como um objeto de reflexão (GUIMARÃES 2001). Assim como seu mestre Paul Ricoeur, deu destaque às reflexões em torno da construção do arquivo por parte dos historiadores. Sua militância, no entanto, também se dirigiu para as próprias políticas públicas, ou para a ausência delas, no que tange a constituição, preservação e acesso aos arquivos em nosso país. Embora não fizesse "história mesmo", o Manoel também padeceu do mal de arquivo, também se deixou fascinar por esses lugares onde muitos jazem arquivados, muitas vezes jazem enterrados, silenciados, a espera e a espreita que um olhar e uma voz historiadora venham lhes tirar do esquecimento.

O Manoel em sua obra refletiu todo tempo sobre os gestos memoráveis e de memorização, sobre os fascínios e perigos das memórias, sobre os impasses do lembrar (GUIMARÃES 2003a; 2007a). Tendo vivido numa Alemanha ainda marcada pelo trauma da Segunda Guerra Mundial, num país que tinha que encarar e trabalhar com a monstruosa memória do holocausto, o Manoel parece ter se dado conta não só do caráter político da memória, mas do caráter existencial e ético do lembrar e do esquecer. Alguns de seus textos refletem sobre os dilemas contemporâneos em torno das memórias, em torno dos usos políticos a que elas são submetidas, em torno dos múltiplos significados dos lugares e das práticas de memória, sobre os conflitos e tensões que cercam a definição do que se deve ou não lembrar. Ao me sentar para escrever um texto para esse dossiê, me pus a pensar justamente sobre as armadilhas da memória. Reflexões que sempre o acompanharam. Me vi na condição de alguém que tem que fazer escolhas na hora que é convocado a lembrar. O que, no espaço deste texto e nos limites estabelecidos para sua escritura, eu poderia e deveria lembrar entre todos os gestos, ações, práticas, escritos ligados ao nome de Manoel Luiz Salgado Guimarães. Ele que por vezes recordo como nome de 
autor, como persona pública, mas que por vezes me vem como o nome de uma pessoa, na intimidade da vida privada, na afetividade de relações fraternas. Me pus a pensar que Manoel Salgado eu desenharia para vocês leitores, que perfil eu delinearia dele, que narrativa eu faria desse sujeito, que omissões seriam inevitáveis ou imperdoáveis, que outros Manoéis possíveis seria preciso dizer aqui. Preferi fazer a escolha por aquele Manoel que para mim teve não apenas uma importância privada, uma importância fraterna muito grande, mas uma importância pública, política, ética, o Manoel Salgado mestre de rigor, o historiador que desempenhou um papel central e decisivo no desenvolvimento dos estudos de historiografia entre nós.

Desculpem se termino este texto com um rapidíssimo ensaio de ego-história. Conheci o Manoel Salgado em um Simpósio Nacional de História realizado no Recife, no ano de 2001. A Associação Nacional de História, sempre a ANPUH-Brasil, a nos aproximar daqueles de quem acompanhamos o trabalho de longe. Eu havia introduzido a disciplina de historiografia brasileira numa reforma curricular feita no curso de graduação em historia da Universidade Federal da Paraíba - Campus de Campina Grande e garimpando textos nacionais que tratassem do assunto, que fossem além dos clássicos de José Honório Rodrigues, Otávio Tarquínio de Souza, Nelson Werneck Sodré, José Roberto do Amaral Lapa, Francisco Falcon e Nilo Odália, o que na época, anos oitenta, era muito difícil, li fascinado o texto que nasceu clássico do Manoel Salgado sobre a historiografia feita no IHGB. Em 2001, em pleno meio dia, no intervalo 150 para o almoço, encontro no estacionamento em frente ao prédio do Centro de Filosofia e Ciências Humanas da UFPE, um grande amigo sergipano, professor da Universidade Federal de Sergipe, Francisco José Alves, que havia conhecido no Simpósio da ANPUH ocorrido em Belém, quando nosso interesse comum por teoria da história nos levou a cursar um minicurso proferido pelo professor Arno Wehling. O Francisco estava acompanhado por mais duas pessoas, que me apresentou, uma delas era o Manoel Salgado. Entre constrangido e fascinado por ter minha bibliografia ali em frente, aceitei o convite para almoçarmos juntos. O que logo me chamou atenção no Manoel foi, além de sua beleza física, de seu apurado senso de humor, aspecto que logo nos identificou, pois sua fina ironia levou ao almoço logo se tornar um momento de muita descontração, onde a presença do riso foi uma constante, foram seus modos refinados, sua figura de gentil homem, de cavalheiro, sua educação refinada, o que costumamos chamar na Paraíba, de sua finura. Mas, também me impressionou sua erudição, seu domínio de autores e ideias, seu conhecimento de uma bibliografia da qual, com muito esforço, vinha também tentando me aproximar. Nasceu ali uma amizade para a vida toda, uma amizade na vida e nas ideias, uma amizade que foi marcada pela criação em conjunto de espaços de discussão de ideias e de afirmação do campo dos estudos historiográficos no Brasil. Ele com sua generosidade me deu essa oportunidade insubstituível de conviver com um mestre e com muitos de seus amigos e discípulos, com os quais muito aprendi, com os quais continuo aprendendo e dos quais me tornei amigo. Embora o rigor talvez não seja propriamente o que me caracterize como historiador, tenho talvez 
uma mente mais indisciplinada para isso, minha indisciplina meio freyreana me leva até a desconfiar de dados rigorismos, por paralisantes da criação que podem ser - e eu sempre me perguntei até que ponto o Manoel partilhava das minhas viagens, embora tenha tido nele um constante ouvinte e interlocutor, além de um prefaciador generoso (GUIMARÃES 2007b) -, ele sempre soube da importância que mais do que seus escritos, suas palavras, suas avaliações e opiniões sempre tiveram para mim. Ele foi também o meu mestre de rigor. Embora tenha, assim como seus mestres de rigor, apontado para a escrita da história como o momento decisivo de nossa prática historiadora, o Manoel não deixou de dar bastante ênfase no que seria o segundo momento da "operação historiográfica", ou seja, a fase da disciplina, para Michel de Certeau, ou a fase da explicação/compreensão, para Ricoeur. Eu talvez enfatize em demasia a terceira fase, embora não deixe de ter preocupações disciplinares e de ordem teórico-metodológica. Se isso agradava meu mestre, infelizmente não mais saberei.

Descendente de portugueses, talvez o Manoel tenha sempre querido fazer jus ao seu nome. Como nos lembra Temístocles Cezar (GUIMARÃES 2011), tal como seus antepassados, o Manoel foi um viajante, um homem salgado pelas travessias dos mares. Manoel em suas viagens, sempre dirigidas por todos os instrumentos de orientação possível, uniu espaços de pensamento que estiveram apartados, nos abriu os olhos e os portos para outros navegantes e outras ideias que velejavam em outros mares. Uniu a tradição historiográfica alemã, na qual foi formado, à tradição da historiografia francesa, sem descurar do aporte de outras culturas historiográficas. A obra do Manoel significou uma lufada de ar fresco, a chegada de uma nau trazendo boas novas. Como um viajante, um migrante na vida e no pensamento - talvez por isso tenha feito do Ceará e dos cearenses sua terra e conterrâneos eletivos, tenha encontrado nos paus-de-arara seus parentes de viagem, seus amigos de mar, sol e sal -, o Manoel nos proporcionou como professor, como palestrante, como orientador, numa simples conversa, viagens inesquecíveis para o mundo do pensamento, do passado e dos sentimentos. Quem o conheceu sabe como gostava de contar sobre suas viagens, como gostava de escutar sobre as viagens alheias, mesmo que fosse uma acidentada viagem ao deserto do Jalapão. Viajava nos textos que lia, convidava para viajarmos nos textos que escrevia, transformava as aulas que ministrava numa viagem sem alucinógenos. Manoel nos ensinou que é possível rigor na viagem, método na pescaria e na caça em textos alheios, meticulosidade nas travessias. Ninguém assume o nome Salgado impunemente, ele se destina a dar saber e sabor as vidas das quais fala e com as quais convive. Ser o sal da terra, da nossa terra, em termos de estudos historiográficos, foi a grande obra e tarefa do mestre Manoel Luiz Salgado Guimarães. Aquele que acima de tudo, foi tempero e alimento em nossas vidas. Aquele que não recusava o convite para um bom repasto, que não resistia aos atrativos de um prato, de um doce, de um salgado, sabia que o sabor é fundamental em tudo o que se faz, que a escrita da história pode ser alimento para paladares rigorosos e refinados como o seu, mas que pode também desandar em gororobas intragáveis. Se ele foi um mestre de rigor, isso não implicou numa obra e numa vida insípida e sensaborona. 
Seus escritos, suas palavras, suas ideias, roliças de tanto serem lapidadas, rolavam acicatando nossas papilas gustativas cerebrais, provocando que novas ideias fossem salivadas, que saíssemos de sua escuta umedecidos e em estado interessante, prontos para dar vida a novos escritos e a novos saberes.

Termino convidando a que todos façamos jus a nosso mestre de rigor. Que continuemos a obra que ele iniciou, essa é a dívida que temos para com ele. Afinal, como chama atenção Certeau, um dos seus mestres de rigor, o historiador é alguém sempre em dívida com os mortos, com aqueles que se foram e hoje já se dizem no passado. Se temos uma dívida com o Manoel, por tudo que ele significou para nós, em nossas vidas e em nossas obras, que a resgatemos, continuando por ele a obra que iniciou, trilhando o caminho do rigor e do respeito pelo outro, pelo diferente, pelo discrepante, pelo distinto, que sempre foi a sua marca. Façamos do campo dos estudos de historiografia não apenas um lugar de viagem, mas também um lugar de encontro, de partilhamento, tal como ele construiu em vida. Quem viaja pode fazê-lo para fugir, mas também para encontrar, para se encontrar. As viagens historiográficas do Manoel fizeram a historiografia brasileira encontrar um lugar próprio, colocar-se entre as demais historiografias com um estatuto singular, fez com que superássemos, também nesse campo, nosso complexo de vira-latas e víssemos o que fomos e somos capazes de produzir, a contribuição original ou não que pudemos dar, dimensionando e redimensionando a nossa contribuição, estando essa submetida ou não a um rigor na forma e no conteúdo. Mas acima

152 de tudo, lembrarmos que, além do rigor que o notabilizava, o Manoel sabia rir, sabia rir de si mesmo, atitude de máxima sabedoria, pois evita o pedantismo e a arrogância e mantém a humildade e a simplicidade necessárias para que se continue ouvindo, respeitando e aprendendo com os demais; sabia rir das situações que enfrentava; com aqueles com quem convivia; daquilo de muito sério com que se ocupava; pois como proposto por Hayden White, a ironia é o tropos que caracteriza o trabalho historiográfico em nossos dias, e o próprio trabalho no campo da historiografia poder-se-ia dizer irônico, já que o texto de historiografia visa por em suspeição e em suspenso às regras que produziram dada escrita da história, ele visa suspender a adesão imediata, por em questão a evidência do texto do historiador. O campo dos estudos de historiografia, do qual ele foi um pioneiro, afirma-se à medida mesmo que se adota uma atitude de distanciamento, de retorno irônico sobre aquilo que fazem os historiadores, em dada época, em dada sociedade, em dado regime de historicidade (HARTOG 2013). O fato de ter sido um amante do riso talvez nos permita concluir que a sua melhor definição poderia ser: Manoel Salgado, um mestre do ri(r)gor.

\section{Referências bibliográficas}

CERTEAU, Michel de. A Escrita da História. $2^{a}$ ed. Rio de Janeiro: ForenseUniversitária, 2002.

ELIAS, Norbert. La Dynamique de I'Occident. Paris: Calmann-Lévy, 1975. 
FOUCAULT, Michel. A Arqueologia do Saber. $2^{a}$ ed. Rio de Janeiro: ForenseUniversitária, 1986.

GUIMARÃES, Manoel Luiz Salgado. Estudos sobre a Escrita da História. Rio de Janeiro: 7 Letras, 2007a.

Prefácio. In: ALBUQUERQUE JR., Durval Muniz. História: a arte de inventar o passado. Bauru: EDUSC, 2007b, p. 15-18.

. História e nação: uma pedagogia para a modernidade. In: MAGALDI, Ana Maria; ALVES, Cláudia; GONDRA, José G. (orgs.). Educação no Brasil: história, cultura e política. Bragança Paulista: Edusf, 2003b, p. 183-202.

Historiografia e Nação no Brasil (1838-1857). Rio de Janeiro: EDUERJ, 2011.

- Livro de Fontes da Historiografia Brasileira. Rio de Janeiro: EDUERJ, 2010.

- Memória, história e historiografia. In: BITTENCOURT, José Neves; BENCHETRIT, Sara Fassa; TOSTES, Vera Lúcia (orgs.). História representada: o dilema dos museus. Rio de Janeiro: Museu Histórico Nacional, 2003a, p. 75-96.

- Nação e civilização nos trópicos: o IHGB e o projeto de uma História Nacional. Rio de Janeiro: Estudos Históricos, vol. 1, n. 1, 1998, p. 5-27.

. O presente do passado: as artes de Clio em tempos de memória. In: ABREU, Martha; SOIHET, Raquel; GONTIJO, Rebeca (orgs.). Cultura política e limites do passado: historiografia e ensino de história. Rio de Janeiro: Civilização Brasileira, 2007, p. 23-41.

Para reescrever o passado como história: o IHGB e a Sociedade dos Antiquários do Norte. In: HEIZER, Alda; VIDEIRA, Antônio A. P. Ciência, civilização e império nos trópicos. Rio de Janeiro: Access, 2001, p. 1-28.

HARTOG, François. Regimes de Historicidade: presentismo e experiências do tempo. Belo Horizonte: Autêntica, 2013.

ROCOEUR, Paul. A Memória, a História, o Esquecimento. Campinas: Ed. da Unicamp, 2007. 